\title{
EL VERDUGO (1964) Y LA TRAGEDIA GROTESCA
}

Juan A. Ríos CARratalá Universidad de Alicante

Los amantes de las frases hechas afirman que una imagen vale más que mil palabras. Es fácil rebatir esta idea repetida con escasos argumentos. No obstante, en el caso de El verdugo (1964) una imagen no sólo ha estado en el origen de la considerada como una de las mejores películas del cine español, sino también de un aluvión de críticas y estudios. Luis García Berlanga ha contado, en reiteradas ocasiones, la impresión que le causó el relato del ajusticiamiento de una mujer en Valencia presenciado por un amigo suyo. De esta circunstancia surgió la imagen que se convertiría en una inolvidable escena de la película: una dependencia carcelaria, fría y desolada, en la que coinciden dos víctimas, el reo y el verdugo, ambos rodeados de grupos que les encaminan a una puerta de salida sin retorno posible, real o metafórico según los casos. La cámara fija, como nuestra mirada, y el encuadre en picado. Pocas veces una imagen ha sido capaz de decir tanto, pero era preciso llegar hasta la misma de manera lógica y coherente. Fue la compleja tarea asumida por el director y Rafael Azcona, responsables de un guión transformado en una película de la que es difícil parar de hablar y escribir.

La historia de José Luis, el personaje interpretado por Nino Manfredi, ejemplifica a la perfección la trayectoria de un atrapado por la vida. Como tal se inserta en el conjunto de las creaciones de sus autores, por encima de su específica condición de verdugo, punto final de una evolución que centra el interés de los guionistas. Esta línea de interpretación ha acabado 
imponiéndose a la denuncia de la pena de muerte, también presente en la película. Sin anularla, por supuesto; pero el interés que sigue suscitando $E l$ verdugo se relaciona más con una circunstancia próxima a la mayoría de los espectadores. Por desgracia, dicha pena permanece cerca de nosotros, aunque de manera distinta a la de 1963, año del rodaje y la ejecución de Julián Grimau ${ }^{1}$. Hoy es una noticia que nos produce un rechazo mayoritario, al parecer no compartido en otros países. Está en los medios de comunicación, pero no en una experiencia cotidiana en la que, sin embargo, resulta fácil encontrar otros casos, menos llamativos, de atrapados por la vida. Nosotros mismos podemos estarlo por nuestra incapacidad para decir no, como el atribulado José Luis.

El matrimonio y la casa en propiedad, circunstancias cotidianas, hipotecan la vida de un protagonista que intenta escapar de su soledad y termina, literalmente, arrastrándose hacia un destino trágico. Al final, después de renegar de su condición, queda sumido en un cínico silencio para emprender el viaje de vuelta desde Mallorca, donde se ha estrenado como verdugo. Un trayecto que imaginamos abundante en reproches no dichos aunque escuchados; y asumidos hasta horadar su conciencia. El suegro la dejó a buen recaudo hace muchos años y cuida del nieto. Es el único del trío protagonista que jamás manifiesta angustia. Mientras, la interesada y solícita esposa procura la comodidad de su marido, un José Luis sin escapatoria en un barco que, como su vida, no puede gobernar. En ese desenlace abierto, en la continuidad que se intuye tras lo visto, captamos una carga de profundidad que induce a la reflexión. Tal vez nos produzca desasosiego. La relacionada con la pena de muerte podemos objetivarla; es cosa de los otros, de quienes detentan un poder capaz de mantener una legislación contraria a los derechos humanos. Pero aquí se nos habla de alguien llamado José Luis. Y este tipo de destinos nos resulta cercano en lo fundamental. No hace falta convertirse en verdugo para comprobar el precio de una hipoteca cuando nos dejamos atrapar por la vida, por un destino que implica la pérdida de la libertad del individuo en una sociedad cuyo pragmatismo se impone, con tal fuerza que llega a ser tan ineludible como el intento de supervivencia.

La amplia bibliografía crítica sobre la película ha explicado un proceso creativo sobre el que nada puedo añadir. Pero cuando conocí las afirma-

1. Aparte del citado dirigente comunista, en 1963 también fueron ejecutados dos anarquistas acusados de un atentado que no cometieron, tal y como se ha sabido al ser emitido por televisión el testimonio de quienes lo realizaron. En cualquier caso, en 1963 la pena de muerte distaba mucho de ser algo lejano para los españoles. 
ciones de Román Gubern (CAÑEQUE y GRAU, 1991:230) y Fernando Fernán-Gómez (2002:128) acerca de su consideración como una «tragedia grotesca» y, poco después, El verdugo se ponía en escena gracias a la magnífica adaptación de Bernardo Sánchez Salas ${ }^{2}$, pensé hasta qué punto ese proceso no era también el de las tragedias grotescas, denominación acuñada por Ramón Pérez de Ayala tras el estreno de La señorita de Trevélez (1916) y otras obras de Carlos Arniches ${ }^{3}$.

Tanto Luis García Berlanga como Rafael Azcona han manifestado en reiteradas ocasiones su admiración por el dramaturgo alicantino y, más en concreto, por el género del sainete considerado como una de sus fuentes de creación. Mejor sería hablar de lo sainetesco, pues como intenté demostrar (1997) la pretensión de estos y otros cineastas coetáneos nunca fue la adaptación del sainete, sino la utilización de algunas de sus características básicas en una peculiar y fértil mezcla. El resultado es, a menudo, una lectura del género alejada de la originaria, entendiendo como tal la de Carlos Arniches y otros autores de su época, un tanto trasnochados para las pretensiones de unos cineastas con impulso renovador.

Había en todos ellos una vocación realista, coherente con las corrientes que a lo largo de los años cincuenta y principios de los sesenta se daban en el panorama creativo español. En Berlanga y Azcona esta orientación muestra rasgos peculiares, alejados de los cánones de un realismo crítico con el que, desde el silencio, polemizaron mediante unas películas cuya profunda repercusión llega hasta nuestros días. Al margen de otras cuestiones, su poética partía de una superación de los esquemas genéricos y una apuesta por la tragicomedia, más fiel a una realidad en la que drama y humor apenas se pueden aislar. En esa dirección pronto encontraron las tragedias grotescas de Carlos Arniches. Juan Antonio Bardem hizo, en Calle Mayor (1956), una lectura exclusivamente dramática de La señorita de Trevélez. El resultado es coherente con las pretensiones de un cineasta alejado de lo sainetesco y capaz de captar las posibilidades de un esquema argumental adaptable a sus propias circunstancias históricas e ideológicas (RIOS CARRATALÁ, 1999). Berlanga y Azcona nunca se han centrado en una obra determinada. Su interés por un segmento de la creación teatral de Carlos Arniches ha estado vinculado a un concepto de la tragicomedia

2. Esta coproducción de Teatro de la Danza, Barbotegui y La Llave Maestra, dirigida por Luis Olmos, tuvo un clamoroso éxito a partir de su estreno en la temporada 2000-2001. Véase $\mathrm{M}^{\mathbf{a}}$ Teresa García-Abad (2002) y Francisco Ernesto Puertas Moya (2002).

3. Defino dicho concepto genérico en la Introducción a mi edición de la citada obra arnichesca (1997). 
que ellos mismos, con distintas variantes, han utilizado en sus películas. Una mezcla superadora de los rígidos convencionalismos genéricos que, paradójicamente, les acerca a un subgénero como es la tragedia grotesca.

No obstante, la fórmula acuñada por Ramón Pérez de Ayala en 1924 es algo más que la citada mezcla. También implica la aparición de unos protagonistas atrapados por la vida, observada siempre como un conjunto de circunstancias concretas e inmediatas. Son unos antihéroes desbordados por una realidad que les impide ser ellos mismos. Tendrán que aparentar, por ejemplo, juventud y coquetería para ocultar el paso del tiempo a una hermana solterona ( La señorita de Trevélez), valor hasta la temeridad para sacar adelante a una hija (Es mi hombre, 1921), locura para que una familia recupere el sentido común (La locura de don Juan, 1923)... José Luis, un pacífico empleado de pompas fúnebres que aspira a trabajar como mecánico en Alemania, tendrá que convertirse en verdugo. Esta transformación, impuesta y contraria a la idiosincrasia de los personajes hasta el punto de provocar la comicidad, se da tanto en las tragedias grotescas de Carlos Arniches como en la película de Berlanga y Azcona. Pero también hay notables diferencias. El humor esperanzado y reconciliador del primero presenta transformaciones concebidas como una fórmula teatral, ya clásica en el ámbito de los géneros cómicos. Divertida y hasta entrañable por su ingenuidad, era capaz de propiciar la aparición de unos recursos de los que hacían gala intérpretes como Valeriano León ${ }^{4}$. Pequeños, frágiles y simpáticos, durante unos momentos se transformaban en héroes para provocar la sonrisa de unos espectadores identificados con quienes aparentaban superar ciertas limitaciones. Luego, en desenlaces donde todo se soluciona -al menos, sobre el escenario-, volvían a su personalidad originaria, aunque a la misma se le sumara la confianza ganada mediante una transformación que nunca cuestiona nada y reafirma la necesidad de acomodarse a las pequeñeces de la cotidianidad.

La transformación de José Luis resulta trágica y, además, irreversible. No es un recurso cómico, a pesar de que genere episodios grotescos que provocan una peculiar sonrisa, sino la recreación de un proceso de miserabilización que los autores detectan y subrayan a partir de una escéptica observación de su entorno. El resultado muestra rasgos menos contrastados en la apariencia del protagonista y, por eso mismo, menos rentables desde el punto de vista de la ficción cómica, pero son identificables por

4. Carlos Arniches concibió varias de sus tragedias grotescas para Valeriano León, que las estrenó en colaboración con su esposa, la actriz Aurora Redondo. 
parte de un espectador que asiste a la lenta y justificada transformación de José Luis.

Amadeo, el experimentado verdugo interpretado por el genial Pepe Isbert, evita el rechazo del espectador y nos parece entrañable gracias a un actor que sintetiza, incluso en su aspecto físico, el sentido de la tragicomedia. Y desde su primera intervención, cuando acaba de ejecutar a un reo y manifiesta que no deja de fumar porque no tiene «coraje», ejemplifica un concepto del humor que, de manera equívoca, se ha asociado con lo «negro». Convendría aducir otras influencias más vinculadas a la tradición española. En cualquier caso, Berlanga y Azcona nunca edulcoran lo que simboliza un trabajo que le ha llevado a la soledad compartida con Carmen, su casadera hija dispuesta a aferrarse a cualquier oportunidad de esquivar el destino de solterona. Otro solitario, José Luis, se acerca a ella y es atrapado. No por una supuesta misoginia, tantas veces citada en relación con las creaciones de Azcona y Berlanga. La misma implicaría una culpabilidad, inexistente en la obra de quienes se limitan a presentar egoísmos o aspiraciones tan comprensibles como mediocres ${ }^{5}$. Carmen no quiere quedarse sola, José Luis la desea y Amadeo pretende disfrutar su jubilación en una casa confortable. No hay culpabilidad alguna en lo que, sin embargo, sólo puede ser satisfecho a un alto precio. El padre y la hija lo pagarán con la tranquilidad que en lo material aporta un involuntario cinismo, si es que cabe hablar de este paradójico concepto. José Luis, incapaz de decir no, se convertirá en un ser ajeno, el verdugo, del cual jamás podrá escapar. Los protagonistas de las tragedias grotescas de Carlos Arniches vuelven a ser quienes eran, se reconcilian consigo mismo tras haber atravesado momentáneamente sus propias fronteras en un aprendizaje que a todos, espectadores incluidos, resulta positivo y hasta aleccionador. José Luis no, porque en las películas de Berlanga y Azcona no cabe el desenlace feliz y reconciliador. Tampoco un aprendizaje en abierta contradicción con el arco que trazan sus personajes: el de la miserabilización ${ }^{6}$.

5. En este sentido resultan reveladoras las palabras del director sobre el personaje de Enma Penella: «recuerdo que había pensado alguna vez en perfilar el personaje de ella como un personaje mucho más maquiavélico y manipulador, que llegaba a quedarse embarazada de forma consciente. En aquella época [...] una mujer que consiguiera quedarse embarazada tenía un ochenta por ciento de probabilidades de llevar al altar al señor en cuestión. Lo que sucede es que esa opción la hubiera hecho culpable y a mí no me gusta culpar tan claramente a nadie. En mis películas nadie es culpable. Sólo el grupo, insisto, y de una forma inconsciente, es el gran colectivo devoradon, en Carlos Cañeque y Maite Grau (1991:61).

6. Este concepto ha sido a menudo utilizado por Berlanga en las numerosas entrevistas que ha concedido para hablar de sus películas. Véanse, fundamentalmente, Juan Hernández y Manuel Hidalgo, 
Asimismo, en $E l$ verdugo no encontramos un humor sin aristas, circunscrito a la gracia de un chiste, un juego de palabras o una réplica ocurrente. Carlos Arniches en las tragedias grotescas superó los límites habituales de su teatro cómico, pero con la prudencia de quien se debía a un público que le había encasillado en el mismo. Nunca abandonó, pues, sus habituales recursos para provocar la sonrisa, sacrificando incluso la coherencia de algunos momentos dramáticos. Florita de Trevélez en el desenlace, mientras llora su engaño, hace inoportunos juegos de palabras que contribuyen a insensibilizar al espectador ante su desgracia, mucho más patente en la nobleza del comportamiento de su hermano Gonzalo. Y así también ocurre con otros personajes de las tragedias grotescas, obligados a repartir las abundantes dosis de humor propias de un género que intentaba, ante todo, entretener al público ya conocedor de la trayectoria arnichesca.

En $E l$ verdugo hay humor, pero de unas características radicalmente distintas. Rafael Azcona ha rechazado a menudo el «humor negro». No se identifica con él. Tampoco Luis García Berlanga parece aceptarlo, aunque utilice esta denominación en algunas declaraciones. Les sobran razones para desechar un concepto de imprecisos límites, un comodín utilizado en España de manera irresponsable para referirse a creaciones que en otros contextos jamás se relacionarían con él. Al margen de lo corrosivo y crítico, el humor de la citada película revela su profunda ligazón con los personajes y las situaciones en las que se ven atrapados. Nunca son los instrumentos utilizados para contar un chiste o provocar la sonrisa con un juego de palabras. Su humor brota del interior de unos antihéroes con voluntad de supervivientes o es el fruto del paradójico contraste que les ofrece su propia realidad. Humor y tragedia van así íntimamente unidos en una invitación a la reflexión, ya presente en algunos momentos de las obras arnichescas pero subrayada en esta peculiar tragedia grotesca.

Humor, pues, nunca gratuito ni constante; ligado al sabor agridulce que nos depara una película capaz de permanecer en nuestra memoria. Algunas tragedias grotescas de Carlos Arniches también alcanzan este objetivo, incluso a pesar de las apariencias de unos finales felices donde todo parece quedar cerrado. ;Que viene mi marido! (1918) es un buen ejemplo. Si profundizamos en lo convencional de dichos desenlaces observaremos la continuidad de situaciones que no invitan a la sonrisa. El resucitado Lázaro Bermejo recibe su merecido, pero queda en el aire la no menos

1981; Carlos Cañeque y Maite Grau, 1991; Antonio Gómez Rufo, 1990 y el número monográfico de Nickel Odeon (1996). 
culpable codicia de sus antagonistas. El mensaje regeneracionista de Don Marcelino en La señorita de Trevélez, tan optimista como retórico, no evita que la solterona arrastre su amargura. Podrá irse de viaje con su hermano Gonzalo, pero no olvidar un engaño que le ha marcado. Así también sucede con otros personajes a los que Carlos Arniches ofrece una solución momentánea, más teatral que vital, calculada para satisfacer al espectador que se conforma con un desenlace convencional sin desechar la posibilidad de propiciar, en otro tipo de espectador, una lectura que vaya más allá del limitado espacio del escenario.

El verdugo opta directamente por esta segunda posibilidad. Nadie piensa en un final cerrado y convencional cuando José Luis se embarca en Mallorca de regreso a casa. Su perplejo rostro así lo indica. Tal vez se imponga su voluntad de presentar la renuncia, de no repetir una experiencia que le ha transformado en otro. Pero Carmen y su suegro no le escuchan. Aparentan tranquilidad mientras le dan comida o juegan con el niño a la espera de reencontrarse en su domicilio tras unas cortas vacaciones. Es decir, se aferran a aquello para lo que es necesaria la continuidad de José Luis como verdugo. De ahí la duda del espectador, la ausencia de respuesta a una interrogante irresoluble en tanto que vital.

Carlos Arniches, como autor, era un católico esperanzado con ideas tan sencillas como rotundas en una formulación sin dialéctica posible. No dudaba a la hora de convertirlas en lugares comunes, pues conocía su efecto balsámico en los espectadores. El radical escepticismo de dos agnósticos como Berlanga y Azcona va por otros derroteros. El arco que trazan sus personajes nunca es el de una superación para alcanzar un objetivo, ni siquiera el de un reencuentro enriquecedor consigo mismo tras una momentánea conversión. Fracasan y sobreviven, una paradójica dualidad más amparada en la tradición picaresca que en modelos teatrales como el de Carlos Arniches.

José Luis no es un personaje grotesco, aunque su relación con Carmen y su pánico a ser requerido para ejecutar a un reo le hagan protagonizar situaciones cómicas donde este concepto resulta pertinente. Todos los días lee El Caso con el código penal en la mano, media para evitar peleas callejeras de imprevisibles resultados y vive en una angustia que le hace risible hasta que, en calzoncillos y camiseta, recibe la fatídica carta certificada convocándole a su primera ejecución. Justo cuando, en su casa y en un recién comprado colchón, intentaba gozar con Carmen. Todo tiene un precio.

Tampoco hay una continuidad de lo grotesco en el caso de su suegro, tan acomodado a una realidad que acepta con naturalidad. Pepe Isbert hace creíble a un verdugo que, cuando termina su tarea, se preocupa por 
su tos y busca quien le lleve a casa. Sin subrayados histriónicos, aspecto tétrico y mirada torva de acuerdo con lo previsible en un personaje de su condición. Muestra, por el contrario, sentido común y actúa con la sencillez de una cotidianidad que nos provoca verdadero terror, a diferencia del de tantas otras películas. Su interpretación convierte en entrañable por cercano a quien rechazamos por su condición de verdugo. La misma es presentada más como símbolo tan sólo enunciado que como reflejo de las circunstancias concretas de una realidad, que en este sentido se evitan por innecesarias o se contradicen en aras de la coherencia del film. No echamos de menos un trabajo documental y testimonial como el de Basilio Martín Patino en Queridísimos verdugos (1973). Tampoco la información que nos aportan ensayos como los de Daniel Sueiro: Los verdugos españoles (Madrid, Alfaguara, 1971) y La pena de muerte (Madrid, Alianza, 1974). Nos basta saber cuál es el trabajo del anciano, ver su maletín y, ya que la censura impidió que oyéramos el ruido de su instrumental, escuchar sus peculiares teorías sobre el derecho del reo a una muerte digna.

Berlanga y Azcona no utilizan el trazado grueso para presentar a unos personajes que protagonizan situaciones extremas con una naturalidad que las hace cercanas, incluso cotidianas y, por eso mismo, más terribles. Recordemos que la necesidad de ocupar una plaza de verdugo para conseguir una casa, como el casarse con una anciana para alcanzar el mismo objetivo en El pisito (1958) ${ }^{7}$, de Marco Ferreri, puede considerarse como algo extraordinario y hasta insólito, pero nunca inverosímil o carente de justificación. No confundamos, sobre todo, la solución con el proceso que lleva a la misma. Lo secundario es que José Luis se convierta en verdugo, concepto que en su caso tiene más de parábola que de observación de la realidad ${ }^{8}$. Lo fundamental es la evolución de quien se ve atrapado por la vida, por un cúmulo de circunstancias que le abocan a una decisión extrema que comprendemos. Y en ese proceso el comportamiento de José Luis no cabe considerarlo como grotesco, al menos en un sentido permanente $\mathrm{y}$ definitorio.

7. Pelicula con guión de Rafael Azcona a partir de una novela suya publicada en 1957. Berlanga pudo haberla dirigido y, en cualquier caso, ha manifestado en varias ocasiones su identificación con ella. Véase Azcona, 2005.

8. J.M. Pérez Lozano en 1964 escribió: «Salvo la ventaja que, en orden al contraste -hombre pacifico, profesión espeluznante- tiene el que José Luis sea verdugo, la tesis del film habría quedado sensiblemente igual si José Luis fuese obligado a ser carnicero, carabinero o funcionario del servicio de limpiezas. Pues no es la pena de muerte el tema de la película, sino más bien el de la imposible libertad del hombre, la libertad coaccionada, la imposibilidad de elegir. Y es aquí donde Berlanga [y Azcona] carga toda su desalentada filosofia novitalista», en Benito Herrera y Víctor Iglesias (eds.), 1997: 81. 
Así lo entendieron Nino Manfredi y Juan Echanove (en la versión teatral), optando sobre todo en el primer caso por una interpretación propia de una comedia, que nos acerca un personaje solitario cuyo objetivo es compartir sus pequeñas y justificadas ambiciones. Para conseguirlo se transforma en otro sin que el intérprete recurra a trucos de probada eficacia cómica, sin apenas subrayar el suave deslizamiento hacia el abismo: ese verdugo contrapuesto a la inicial actitud de José Luis. Pero, a diferencia de las transformaciones operadas en las tragedias grotescas de Carlos Arniches, lo cómico no reside en una nueva apariencia del protagonista, que tanto hacía reír a los espectadores de un Valeriano León, por ejemplo, convertido en un temible matón (Es mi hombre), o un Quique Camoiras en un iracundo padre de familia (La locura de don Juan). José Luis no es el apocado y tímido personaje que se transforma en alguien tan diferente como imprevisto para hacernos reír. Sigue siendo él mismo hasta el final, al menos en la apariencia de quien camina hacia el cadalso con traje claro y sombrero de turista; sin demasiados apuntes grotescos, los justos para evitar el patetismo. Su aceptación del puesto de verdugo no es un truco teatral como el empleado por los protagonistas de Carlos Arniches. No se identifica con una careta, reversible en un desenlace feliz donde todo se reconduce. Supone una decisión trágica que le aboca a un destino inexorable. Y en el mismo lo grotesco, a lo sumo, es una mueca ridícula e irrisoria que nada consigue; otros, con paternales palabras, se encargan de empujarle hacia el patíbulo.

Carlos Arniches nunca renunció a impartir lecciones morales, ejemplificadas mediante argumentos cuyos desenlaces funcionan al modo de una fábula. Se dice que los humoristas son, en el fondo, unos moralistas. Habría que matizar, como en tantas otras cuestiones relacionadas con el humor (RÍOS CARRATALÁ, 2005), pero en el teatro de aquella época la actitud del autor alicantino es tan habitual que apenas merece la pena comentarla como rasgo peculiar. Berlanga y Azcona, por el contrario, nunca apuntan en esa dirección. Su radical escepticismo socava un moralismo consustancial con quienes, desde la confianza en sus postulados, intentan compartir con los espectadores un optimismo capaz de solucionar cualquier problema, al menos en el tiempo y el espacio del escenario. La última escena de una tragedia grotesca provoca una sonrisa, velada en ocasiones si pensamos en una situación que sólo se ha solucionado en las citadas coordenadas. En el desenlace de El verdugo se evita lo directamente trágico, e impactante, que habría supuesto terminar con la imagen del patio por donde se arrastra José Luis tras su víctima. Algunos críticos han manifestado su preferencia por este posible final, pero olvidan que esa misma tragedia debe insertarse en el plano de lo cotidiano entrevisto 
cuando la familia parte de Mallorca. Los tres adultos se llevan, en silencio, algo que, aunque se pretenda obviar u olvidar, les acompañará siempre. Sin solución alguna, diluido al margen de la espectacularidad de la citada imagen. Y, lo que es peor para un posible moralismo, sin culpables que como tales tengan que pedir perdón o ser castigados.

En las tragedias grotescas de Carlos Arniches siempre hay un culpable, presentado sin acritud y dispuesto a rectificar tras reconocer las consecuencias de lo que él mismo ha urdido. Su conversión y consecuente perdón forman parte de un desenlace que, sólo en algunas ocasiones, deja entrever un concepto simbólico de culpabilidad que va más allá del personaje concreto. Puede ser el fruto de unas circunstancias sociales y culturales, como el burlador Tito Guiloya de La señorita de Trevélez, o el instrumento utilizado por quienes no se atreven a manifestar su, por ejemplo, codicia (véase el papel desempeñado por «el ingenioso Hidalgo» en iQue viene mi marido!). Pero la delimitación de dichas circunstancias o la presentación del mal (insensibilidad, incultura, codicia...) como algo común y corregible mediante un simple reconocimiento -un antídoto tan teatral, o católico, como falso- permiten que el espectador respire confiado. Sabe donde está el mal; cerca, pero no en él o en alguien concreto. Y, sobre todo, sabe cómo combatirlo. De manera ingenua, tal vez; pero con la seguridad aportada por un autor que, lejos de plantear interrogantes, busca la reafirmación de ideas comunes compartidas con sus espectadores.

Nada similar sucede en $E l$ verdugo. Aunque José Luis se deje atrapar por Carmen y su suegro, sabemos que en realidad ellos no son los culpables. El egoísmo de quienes se aferran a una casa o a un marido no es menor que el del propio José Luis. Y, lo más importante, no es diferente al del resto de los personajes que pululan por las películas de Berlanga y Azcona, donde la solidaridad es una apariencia imposible y el egoísmo preside todos los comportamientos. En Plácido (1961) culmina esa sensación de que cada uno va a lo suyo, sin capacidad para compartir o, al menos, escuchar. Nunca se habló tanto en una película que ejemplifica la incomunicación humana. No representa, sin embargo, una excepción en una filmografía donde el concepto de miserabilización acarrea una culpabilidad tan generalizada que apenas resulta operativa para definir personajes o situaciones. Forma parte de un relativo pesimismo, o una lucidez, que se extiende hasta tal punto que apenas se entreve una alternativa. No la hay en $E l$ verdugo, desolador drama que nos enfrenta a una realidad sin salida. Y, como sucediera en las mejores muestras de la picaresca, sólo cabe aferrarse a la voluntad del superviviente. José Luis se embarca y seguirá vivo, a pesar de todo. Y nosotros con él, aunque más conscientes tras conocer su caso. 
El espíritu crítico del Carlos Arniches de las tragedias grotescas se concreta en un regeneracionismo basado en la sensibilidad y la cultura. Como conceptos ideales, surgidos al margen de unas circunstancias históricas y sociales concretas. Su bienintencionada ingenuidad queda lejos del corrosivo humor de Berlanga y Azcona en El verdugo, donde nada es ideal y todo queda zarandeado o desvirtuado por un sinfín de circunstancias, tan inmediatas como demoledoras. Ellas son las verdaderas protagonistas de esta historia de atrapados por la vida que, como es lógico, no parte de un apriorismo moral o de otro tipo. Carlos Arniches ejemplifica con sus tragedias grotescas un mensaje establecido a priori. Berlanga y Azcona lo encuentran, a su manera, en el propio desarrollo de un drama que no aporta soluciones, sino que nos desazona. Sonreímos y, simultáneamente, nos inquietamos al comprobar la naturaleza de esa sonrisa, velada siempre por una lucidez tan alejada del regeneracionismo arnichesco.

En las tragedias grotescas es frecuente encontrar dosis de ingenio, a menudo como recurso con intención paródica. Aunque Carlos Arniches destacó más por el diálogo que por sus construcciones dramáticas, lo hay en el planteamiento inicial, siempre divertido y ocurrente para cautivar nuestra atención. Al mismo se añaden nuevos enredos y vicisitudes que, si bien reducen la verosimilitud, prueban la voluntad de entretener a los espectadores mediante recursos habituales en el teatro de humor de la época. Berlanga y Azcona, por el contrario, siguen un camino distinto al presentar una situación que no por extraordinaria se aleja de la verosimilitud. Juntar a un empleado de pompas fúnebres, un verdugo y una mujer solitaria entre ambos supone decantarse tal vez por lo subrayado. Puede también invitar a lo grotesco, pero lo bordean unos cineastas que se ciñen a una trabazón argumental donde no se busca la sorpresa o el toque de ingenio, aunque encontremos ocurrencias geniales. Tampoco se utiliza de manera sistemática una estética expresionista para llegar por otros derroteros a una imagen, hasta cierto punto, similar. José Luis, Carmen y el verdugo nos parecen próximos. Como tales se comportan dentro de un realismo alejado del obligado ingenio teatral de las tragedias grotescas y que, a diferencia de Valle-Inclán, sólo subraya para hacer visible lo que no pretende aparecer como deformado.

Carlos Arniches complica el nudo argumental hasta llegar a un desenlace a veces rocambolesco, donde ninguno de los múltiples cabos puede quedar suelto. Apenas parece preocuparle lo precipitado o artificioso que algunos críticos le achacaron. Utiliza un convencionalismo ajustado a lo habitual en aquel marco teatral. Berlanga y Azcona, por el contrario, presentan un nudo tan claro y sencillo como verdaderamente gordiano. No hace falta añadirle dosis de ingenio. Optan por la observación, por el 
deslizamiento lógico y natural hacia unas consecuencias previsibles donde apenas cabe la sorpresa. Esta circunstancia les permite centrarse en la presentación de sus protagonistas. Les vemos trabajar, convivir en sus casas, divertirse..., como si se tratara de la pareja de una obra costumbrista. No lo es El verdugo por lo extraordinario de su punto de partida, pero sí por un tratamiento que inserta al mismo en una realidad que nos parece próxima. Ahí radica la base de la interpretación de la obra que con el tiempo ha prevalecido. Dejamos en un segundo plano la historia de verdugos y penas de muerte para recordar la de José Luis y Carmen, cuyo drama en el fondo no es diferente al de cualquier atrapado por la vida ${ }^{9}$.

Vemos, pues, que la obra de Berlanga y Azcona no comparte algunas características básicas de las tragedias grotescas de Carlos Arniches. No podía ser de otro modo. A pesar de la admiración de ambos, hay un abismo entre el comediógrafo alicantino y unos cineastas que en su colaboración manifestaron tener un mundo creativo peculiar. En el mismo, la influencia arnichesca no se extiende a unos rasgos en buena medida deudores de su dependencia de un público teatral muy concreto. Las tragedias grotescas son el resultado de una etapa en la trayectoria de Carlos Arniches, marcada por la crisis del modelo sainetesco cultivado hasta entonces con enorme éxito y la necesidad de buscar una salida satisfactoria para un renovado público, hasta cierto punto más exigente por su condición social. También está presente la voluntad de un autor que supo compaginar el éxito con un sentido crítico que resulta ingenuo a veces, aunque eficaz de cara a unos espectadores que se sentían concernidos en un marco presidido por las sonrisas. Y ahí radica precisamente una de las claves de la influencia de la que nos ocupamos: el humor.

En las obras de Berlanga y Azcona el humor es una constante. No porque tengan la voluntad de manifestarse como humoristas ${ }^{10}$, concepto

9. M. Vidal Estévez: «El verdugo no es ni mucho menos en primera instancia una diatriba contra la pena de muerte. Es indudable que la cuestiona, aunque sólo indirectamente. Lo que en realidad propone, y articula todas sus estrategias de sentido, es el minucioso relato de una ominosa integración a una sociedad acomodaticia y opresiva, cuyo mayor desafuero es el asesinato legal. Que sea la profesión de verdugo la actividad a ejercer dentro de esa sociedad no es sino la hipérbole significante de sus funestas exigencias, pero muy similares efectos habría producido si se tratase de la desembocadura mediante idénticas estratagemas en el ejercicio de cualquier otro empleo al servicio del Estado», en Julio Pérez Perucha (ed.), 1997:548.

10. Rafael Azcona llegó a Madrid en 1951 siendo un poeta y pronto se convirtió en un «humorista» tras iniciar sus colaboraciones en La Codorniz (véase José Antonio Llera Ruiz, «Rafael Azcona en La Codorniz», en cervantesvirtual.com y Bernardo Sánchez Salas, 2006). «Me quité de poeta para meterme a humorista〉 (Cuando el toro se llama Felipe, Tetuán, Ed. Cremades, 1956, p. 21). Pero, tras una breve 
que consideran restrictivo, sino porque -como ya apuntábamos-su acercamiento a la realidad concreta y coetánea les lleva a incorporar algo que forma parte de la misma. Alejados de los esquemas genéricos usuales en el cine, consideran que la comedia y la tragedia suponen una estilización, y hasta cierto punto una falsificación, de esa realidad que intentan captar con el máximo grado de flexibilidad. Y de mezcla, la que encontramos en una tragicomedia que sería para ellos la superación de unos límites genéricos que también consideran restrictivos. En esta línea encontraron en Carlos Arniches un ejemplo significativo y popular. Berlanga, más locuaz que Azcona a la hora de hablar de sus películas, le cita a menudo. Pero nunca se refiere a obras o rasgos en concreto. Podemos pensar en la composición coral de sus creaciones, la voluntad de reflejar tipos y ambientes populares, la primacía del diálogo sobre la acción, la estética costumbrista... No obstante, lo fundamental es la reivindicación del humor y su inserción en un, para ellos, necesario marco realista en el que convive con el drama o la tragedia. Eso sí, como le decía el Hermano Marcelo a Fabianito, el adolescente poeta de Los muertos no se tocan, nene ${ }^{11}$ : el realismo si no se exagera un poco se queda en nada.

El verdugo es, en buena medida, una tragedia. La de un sujeto incapaz de decir no, que bordea lo irrisorio al modo de las tragedias coetáneas de Alfonso Sastre, ya que se encuentra atrapado por las circunstancias de la vida hasta verse abocado a un destino contrario a su tambaleante voluntad. Pero en su caso el destino carece de un origen metafísico, superior o inextricable. No produce terror por lo desconocido, sino por lo contrario: por su proximidad en un ámbito reconocible y cotidiano. De ahí surge la necesidad del humor, tan eficaz para dar cuenta de las concesiones realizadas por un solitario protagonista que busca arrimo y acomodo al modo de los pícaros, aunque sea mediante instancias con pólizas y certificados de buena conducta. Los de un sujeto como cualquiera de los espectadores, no los papeles de unos verdugos reales que a menudo contaban con expedientes delictivos propios de ámbitos marginales. El resultado, en cualquier caso, es la corrupción ética y moral de quien ha conseguido mujer, casa y trabajo. También la perplejidad, que no admite el comportamiento heroico. Nadie espera el desenlace fatal al modo de tantas tragedias; o novelas como La piedra angular (1891), de Emilia Pardo Bazán (OO.CC., II, 275-

etapa como tal con títulos destacados como Vida del repelente niño Vicente (Madrid, Taurus, 1955), su obra literaria rompe con este encorsetamiento y se adentra por caminos creativos similares a los de sus primeras películas.

11. Novela original de Rafael Azcona (Madrid, Taurus, 1956). Reeditada en Azcona, 1999. 
349), donde un poco convincente verdugo se suicida como única solución posible a sus problemas de conciencia ${ }^{12}$. José Luis es un superviviente. Perplejo y atrapado; incapaz de una resolución tajante y, por eso mismo, propicio para recrear un humor agridulce, corrosivo y lúcido. No oculta la dimensión trágica del protagonista, sino que nos la acerca dotada de esos pequeños detalles y circunstancias que la tragedia, en su formulación clásica, no admite.

Detalles y circunstancias que, gracias a la sabiduría de Berlanga y Azcona a la hora de observar y seleccionar, no restan universalidad a la «fábula negra» -así la denominó Bernardo Sánchez Salas-, que como tal ha pervivido en nuestra memoria. Con su correspondiente valor de enseñanza. No al modo dogmático de tantas fábulas, sino con el relativismo de los entremeses cervantinos (SÁNCHEZ SALAS, 2000), siempre propicios para una duda que nos concierne. La de acabar siendo un «verdugo», condición simbólica que se impone a la circunstancia real de José Luis y su suegro. Por eso mismo, en una España tan distinta a la de los sesenta, ha triunfado una adaptación teatral que retrata lo esencial: la tragicomedia de un individuo atrapado por la vida, perplejo y superviviente. Y los detalles no son accesorios, pues poco hay más allá de una realidad cotidiana donde todo es pequeño y circunstancial. Dejemos la metafísica para los puristas de la tragedia.

En las creaciones de Berlanga y Azcona apenas hay lugar para los sentimientos. Los bordean con relativa impasibilidad o muestran su desconfianza hacia los mismos mediante la desvalorización, pero desde una actitud creativa respetuosa con sus personajes. Nunca son peleles y lo grotesco, cuando aparece, dista mucho de provocar una perspectiva de superioridad en el espectador. Tampoco Carlos Arniches, como buen humorista, parece engañarse al respecto. El amor en sus obras constituye una solución práctica o un acomodo. Es fugaz y, con el tiempo, risible. Marca así la pauta para otros sentimientos observados con menos sentido corrosivo que en Azcona y Berlanga, pero con similar escepticismo. El habitual en un humorista pendiente de los detalles, del sinfín de circunstancias que alejan a sus protagonistas de cualquier concepto ideal. No para caer necesariamente en los límites de lo grotesco - concepto algo radical que ni el propio Valle-Inclán recreó siempre con exclusividad-, sino en los de una tragicomedia de atrapados por la vida.

12. En 1971 también se suicidó uno de los últimos verdugos españoles, casado y con once hijos. Pocos, realmente pocos, alcanzaron una vejez plácida y feliz como la que se intuye para el Amadeo de Berlanga y Azcona. 
No conviene pensar, pues, en denominaciones genéricas para relacionar a quien como Carlos Arniches dudó a menudo a la hora de utilizarlas y quienes, como Berlanga y Azcona, han manifestado su voluntad de no sujetarse a unos límites que no admiten. Su relación se establece por la vía del humor -corrosivo para cualquier clasificación genérica- y la de un concepto tan vinculado al mismo como el de los atrapados por la vida. Con él sonreímos y, simultáneamente, nos llega la amarga percepción de una proximidad de la que resulta difícil desprenderse y sólo es llevadera con la voluntad del superviviente. 


\section{BIBLIOGRAFÍA}

Arniches, Carlos, La señorita de Trevélez. Los caciques, ed. Juan A. Ríos Carratalá, Madrid, Castalia, 1997.

Azcona, Rafael, Estrafalario/1, Madrid, Alfaguara, 1999.

- El pisito, ed. Juan A. Ríos Carratalá, Madrid, Cátedra, 2005.

Azcona, Rafael y Luis G. BERLANGA, El Verdugo, Madrid, Alma Plot, 2000. Edición digital de la versión teatral de Bernardo Sánchez Salas en cervantesvirtual.com.

CaÑeque, Carlos y Maite GRAU, „Bienvenido, Mr. Berlanga!, Barcelona, Destino, 1991.

Frugone, Juan Carlos, Rafael Azcona: atrapados por la vida, Valladolid, Seminci, 1987. Edición digital en cervantesvirtual.com.

Fernán-Gómez, Fernando, Puro teatro y algo más, Madrid, Alba, 2002.

GARCíA-ABAB, Ma Teresa, "La profecía meyorholdiana: hacia la cinematización de la escena", en José ROMERA CASTILLO (ed.), 2002:341350.

García Jiménez, Jesús, La poética de Berlanga, Madrid, Tarvos, 2000.

Gómez. Rufo, Antonio, Berlanga, contra el poder y la gloria, Madrid, Temas de Hoy, 1990.

Hernández, Juan y Manuel HIDALGO, El último austrohúngaro: Conversaciones con Berlanga, Barcelona, Anagrama, 1981.

Herrera, Benito y Víctor IGLESIAS (eds.), Rafael Azcona, guionista,

Cádiz, XXIX Muestra Cinematográfica del Atlántico, 1997.

Pardo BazÁn, Emilia, OO.CC., II, Madrid, Aguilar, 1964.

Pérez Perucha, Julio (ed.), Antología crítica del cine español, 1906-1995, Madrid, Cátedra, 1997.

Puertas Moya, Francisco Ernesto, "Revisión de la pena de muerte: El Verdugo, del cine al teatro", en ROMERA CASTILLO, 2002:487-500.

Rios Carratalá, Juan A., Lo sainetesco en el cine español, Alicante, Universidad de Alicante, 1997.

- La ciudad provinciana. Literatura y cine en torno a Calle Mayor, Alicante, Universidad de Alicante, 1999.

- La memoria del humor, Alicante, Universidad de Alicante, 2005.

Romera Castillo, José (ed.), Del teatro al cine y la televisión en la segunda mitad del siglo $X X$, Madrid, Visor, 2002.

Ruiz SANZ, Mario, El Verdugo: un retrato satírico del asesino legal, Valencia, Tirant lo Blanch, 2003.

SÁnChez Salas, Bernardo, "El entremés del verdugo", El Cultural, 9-I2000 , p. 45.

- Rafael Azcona: hablar el guión, Madrid, Cátedra, 2006. 
VV.AA., El Verdugo/Le Bourreau, en Co-textes, n 36, Montpellier, Université Paul Valéry, 1977.

VV.AA., Número monográfico dedicado a Berlanga, Nickel Odeon, $\mathrm{n}^{\circ} 3$ (1996).

VV.AA., Voir et lire García Berlanga. Hispanistica XX, Université de Bourgogne, 1998.

VV.AA., Le sexe, le rire et la mort. Essais sur Le Bourreau de Luis García Berlanga, Nantes, Université de Nantes, 1999. 